\title{
A SURVEY OF ARMOURED SCALE INSECTS ON KIWIFRUIT SHELTER
}

\author{
L.E. JAMIESON ${ }^{1}$, S. DOBSON ${ }^{2}$, J. CAVE $^{1}$ and P.S. STEVENS ${ }^{1}$
}

${ }^{1}$ The Horticulture and Food Research Institute of New Zealand Ltd., Private Bag 92169, Auckland, New Zealand

${ }^{2}$ The Horticulture and Food Research Institute of New Zealand Ltd., No. 1 Rd, RD2, Te Puke, New Zealand

Corresponding author: ljamieson@hortresearch.co.nz

\begin{abstract}
Scale infested kiwifruit continues to be a problem despite regular monitoring and spraying. Shelterbelt trees may be a source of scale insect infestations in kiwifruit vines. A survey of armoured scale insects in 12 common species of shelterbelt trees used in kiwifruit orchards was carried out. Bark samples were removed and the density of scale insects and species composition was determined. Japanese cedar as a shelterbelt species is unlikely to be a significant host for scale insects whereas Balsam poplar, willow and leyland cypress were more likely to host high populations. Shelterbelts in Northland, Auckland and Gisborne generally had higher levels of scale insects than the same species in the Bay of Plenty and Nelson. Greedy or latania scale (Hemiberlesia spp.) was found more frequently than oleander scale (Aspidiotus nerii).

Keywords: armoured scale, shelterbelt trees, kiwifruit.
\end{abstract}

\section{INTRODUCTION}

Greedy scale Hemiberlesia rapax (Comstock), latania scale Hemiberlesia lataniae (Signoret) and oleander scale Aspidiotus nerii Bouché are the armoured scale insect species most commonly found on kiwifruit in New Zealand (Berry et al. 1989). Despite regular monitoring and spraying of scale insects in kiwifruit blocks, scale-infested fruit continues to be a problem in some export markets.

Adults of greedy, latania and oleander scale insects lay eggs that hatch into mobile crawlers which then disperse by crawling and/or by wind currents before they settle, moult and lose their legs. The immigration of scale insects into kiwifruit vines from nearby host plants has been demonstrated by Blank et al. (1990).

Armoured scale insects have a wide range of host plants (McKenzie 1956; Spiller \& Wise 1982) which includes many tree species used as shelterbelts around kiwifruit orchards. Some shelterbelt species may be more suitable for scale insect development than others and therefore harbour higher populations. In order to identify species of shelterbelt trees that may contribute most to scale insect populations in kiwifruit, a national survey was carried out.

\section{METHODS}

In January and April 2001, bark samples from 12 shelterbelt tree species in six kiwifruit growing regions (Northland, Auckland, Eastern Bay of Plenty, Western Bay of Plenty, Gisborne and Nelson) were collected. Within each orchard, ten trees within a shelterbelt adjacent to kiwifruit vines were tagged and sampled. The species of shelterbelt trees and number of orchards from which each species was sampled are shown in Table 1. The same shelterbelt trees were sampled on both occasions. A thin section of bark (approximately $50 \mathrm{~cm}^{2}$ ) was removed using a knife drawn down the trunk at 
approximately 1-2 $\mathrm{m}$ above the ground. Individual bark samples were placed in plastic bags and stored at $18^{\circ} \mathrm{C}$ until assessment.

The numbers and species composition of scale insects on bark samples were determined using a stereomicroscope. The colour and shape of the scale insect cap was used to distinguish between greedy or latania scale, and oleander scale. Greedy or latania scale is close to conical in shape with the brown exuviae (or central 'plate') towards the edge of the scale cover. Oleander scale is flatter than greedy or latania scale with pale yellowish exuviae situated centrally on the scale cover (Morales 1988). To reliably distinguish greedy scale from latania scale compound microscopic examination of mature females is necessary. Latania scale has perivulvular pores present while greedy scale does not (Morales 1988). Any live, mature scale found was slide-mounted in lactic acid and examined for diagnostic characters.

The area of each bark sample was also measured using a transparent $1 \mathrm{~cm}^{2}$ grid to obtain the number of scale insects per unit area of bark.

The numbers of scale insects per unit area of bark were compared between shelter species and regions using Analysis of Variance (ANOVA). Least Significant Differences were calculated to separate samples if the ANOVA indicated significant differences $(\mathrm{P}<0.05)$. All analyses were carried out using the statistics software SAS (release 6.12).

\section{RESULTS AND DISCUSSION}

Total numbers of scale insects on the samples are reported, even though most of them were dead when sampled. The presence of high numbers of dead scale insects is a function of the plant part that was sampled. Scale insects remain firmly attached to plants even after they have died. While dead scale insects on leaves are 'lost' when leaves drop, dead scale insects can remain on woody parts of the plant for long periods. The presence of dead scale insects on bark therefore provides a historical view of host plant suitability that is not as influenced by the time of the season as samples collected from leaves or fruit. The average area of bark sample taken was $43.9 \mathrm{~cm}^{2}$. All results are presented as the total number of scale insects per $50 \mathrm{~cm}^{2}$ of bark.

Combining results from all regions, there were significant differences in scale insect infestation of different shelterbelt species (Figs 1a \& 1b). Armoured scale insects are very polyphagous and appear to be capable of developing on almost any woody plant (McKenzie 1956). However, like any polyphagous insect, development is faster on some hosts than on others (Grout et al. 1989) and also sometimes on different parts of the same plant (Carroll \& Luck 1984). While some shelter belt species are capable of hosting high populations of scale insects, they do not necessarily do so in all situations. Results from individual shelterbelt species within a region were highly variable (data not presented). The patchy nature of scale insect infestation means that it was not easy to categorise individual shelterbelt species in terms of their absolute risk of contributing to scale insect problems on kiwifruit vines. Although no scale insects were recovered from pine and feijoa shelterbelts, these trees have previously been listed as a host plant of oleander scale (Spiller \& Wise 1982) and greedy scale (Anon. 2002) respectively. The absence of scale insects on pine and feijoa may be due to the relatively few samples collected from these species during this survey (only eight pine and four feijoa shelterbelts were sampled). The lack of scale insects on cedar can be asserted with greater confidence as 22 cedar shelterbelts were sampled from the six kiwifruit growing regions and the presence of scale insects would have been expected if this species was a suitable host. Balsam poplar, willow and leyland cypress appear to have a greater risk of having relatively high infestations of scale insects. Lombardy poplar, which is known to be a principal host of latania scale (Hill \& Allan 1990), did not harbour high levels of scale insects in this survey, probably because many of these shelters are routinely sprayed specifically to control scale insects. 
(a)
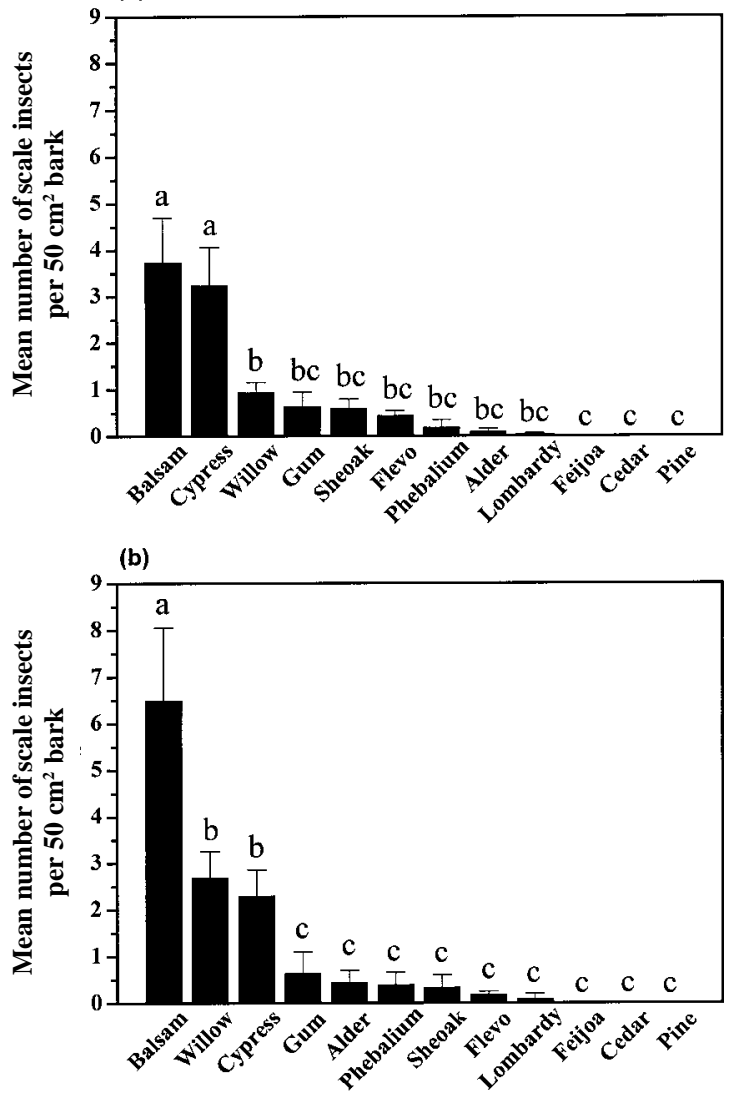

FIGURE 1: Mean number of live and dead scale insects found on different shelterbelt species adjacent to kiwifruit orchards in 6 regions. (a) January survey. (b) April survey. Shelter belt species with the same letter above the bars are not significantly different.

In general, infestations of scale insects on shelter trees in Northland, Auckland or Gisborne were greater than in the Bay of Plenty or Nelson (Tables $1 \& 2$ ). These regional differences may at least be partially influenced by climate. Scale insects generally have two distinct generations each season (Blank et al. 2000), but higher summer temperatures and prolonged warm conditions in autumn may result in a partial third generation with a further period of crawler release. A temperature-driven simulation model of greedy scale development on kiwifruit predicted scale insect populations after 170 days to be $80 \%$ greater at Kerikeri in Northland than in Nelson (Greaves et al. 1994).

Greedy or latania scale were more frequently found than oleander scale in all regions (Table 3). As the majority of scale insects collected from bark samples were dead or immature, most could not be identified beyond the genus level. Most of the scale insects that could be identified to species level $(n=53)$ were from Northland and $90.6 \%$ of these were latania scale. Only one greedy scale was identified from Auckland, and eight from 


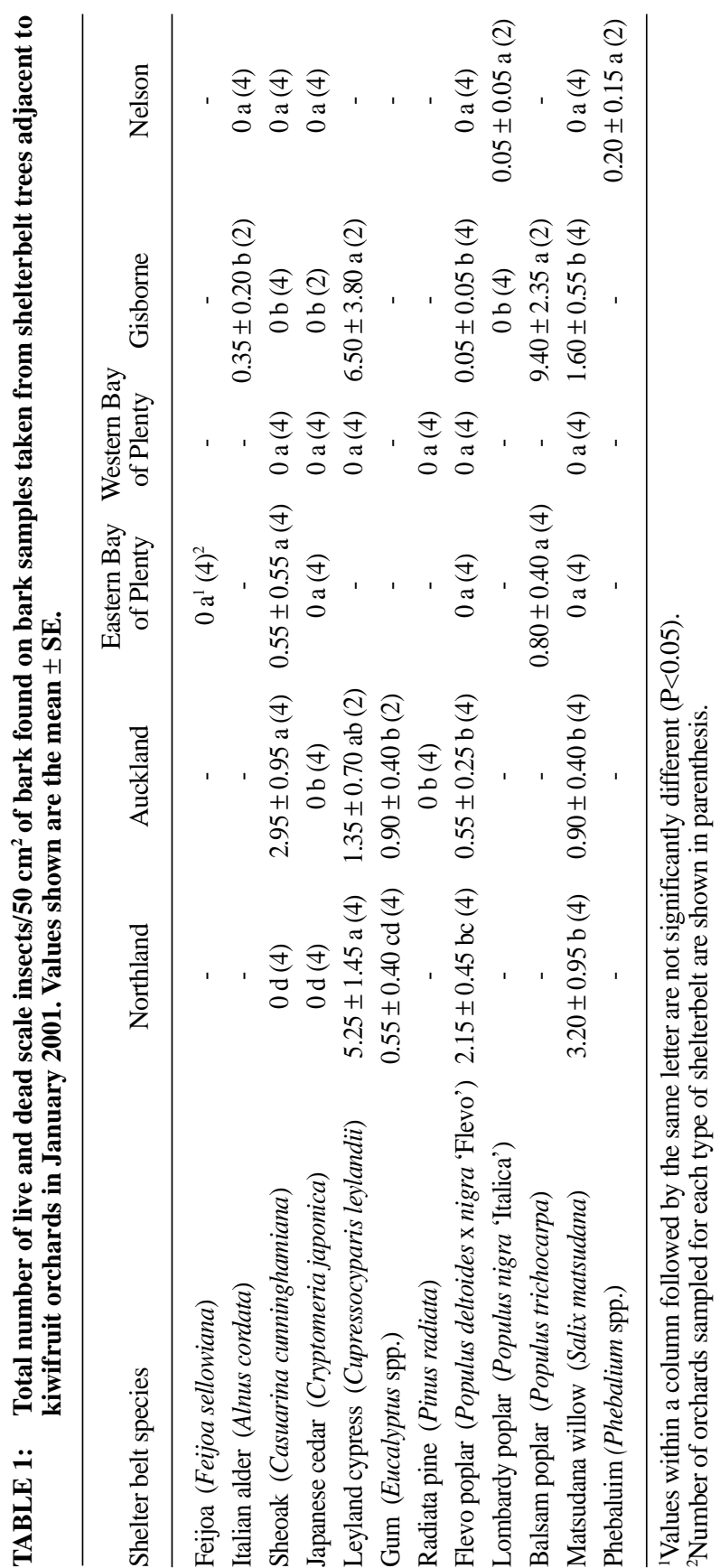




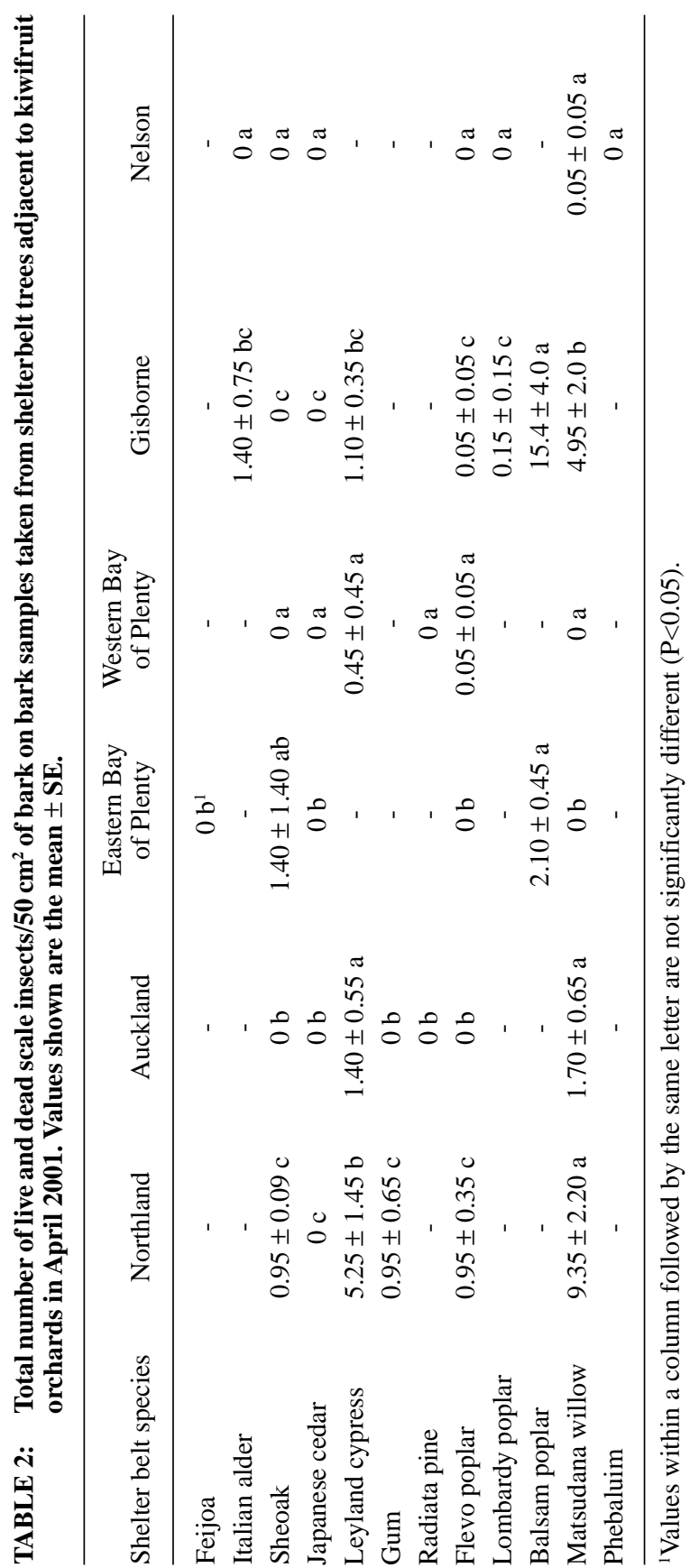


each of the Eastern and Western Bay of Plenty, and no latania scale insects were found in these three regions. A single live mature scale insect from Gisborne was identified as latania scale.

TABLE 3: Species composition (\% of total) of scale insects identified on shelterbelt trees adjacent to kiwifruit orchards.

\begin{tabular}{lccc}
\hline Region & $\mathrm{n}$ & Greedy or latania scale & Oleander scale \\
\hline Northland & 444 & 97.3 & 2.7 \\
Auckland & 134 & 92.6 & 7.4 \\
Eastern Bay of Plenty & 88 & 84.8 & 15.2 \\
Western Bay of Plenty & 9 & 100.0 & 0 \\
Gisborne & 307 & 91.2 & 8.8 \\
Nelson & 9 & 100.0 & 0 \\
\hline
\end{tabular}

The extent to which 'scale invasion' of kiwifruit from adjacent host plants contributes to high scale populations within the kiwifruit vine is unknown. Blank et al. (1990) recorded a peak scale invasion level of 8.7 scale/100 kiwifruit leaves per day and noted that scale settlement was higher in kiwifruit plants closest to other host plants. Scale invasion can be reduced if badly infested host plants are removed or regularly sprayed after trimming (Blank et al. 1990). However, the issues of conserving natural enemies of kiwifruit pests on shelterbelts (Charles et al. 1995; Hill \& Allan 1989) and minimizing the risk of pests becoming resistant to insecticides (Suckling 1984) need to be carefully considered prior to any spraying of shelterbelt trees.

The next important step in this research would be an attempt to quantify whether or not the different shelterbelt species affect scale populations on the adjacent kiwifruit by comparing orchards having the 'low-risk' Japanese cedar shelterbelts with those orchards planted with shelterbelt species that were identified as more suitable hosts of scale insects.

\section{CONCLUSIONS}

This survey identified Japanese cedar as a shelterbelt species that is unlikely to be a significant host for scale insects. Balsam poplar, willow and leyland cypress were identified as species most likely to host high infestations of scale insects. Greedy or latania scale insects were more common than oleander scale insects on the bark of shelterbelt trees in kiwifruit growing regions in New Zealand.

\section{ACKNOWLEDGMENTS}

We would like to thank N. Page, A. Chhagan and E.J. Cutie for technical assistance; J.G. Charles and J. Tyson for comments on the draft manuscript; the many people who helped us to locate sampling sites; the growers who let us sample on their properties; and Zespri Group Limited for providing funds to carry out this research.

\section{REFERENCES}

Anon. 2002: Plant Pest Information Network (PPIN) Database, Ministry of Agriculture and Forestry, New Zealand.

Berry, J.A.; Morales, C.F.; Hill, M.G., Lofroth; B.J.; Allan, D.J. 1989: The incidence of three diaspid scales on kiwifruit in New Zealand. Proc. $42^{\text {nd }}$ N.Z. Weed and Pest Control Conf.: 82-186.

Blank, R.H.; Gill, G.S.C.; Kelly, J.M. 2000: Development and mortality of greedy scale (Homoptera: Diaspididae) at constant temperatures. Environ. Entomol. 29(5): 934-942. 
Blank, R.H.; Olson, M.H.; Lo, P.L; 1990: Armoured scale (Hemiptera: Diaspididae) aerial invasion into kiwifruit orchards from adjacent host plants. N.Z. J. Crop Hort. Sci. (18): 81-87.

Carroll, D.P.; Luck, R.P. 1984: Bionomics of California red scale, Aonidiella aurnatii (Maskell) (Homoptera: Diaspididae) on orange fruits, leaves and wood in California's San Joaquin Valley. Environ. Entomol. 13: 847-853.

Charles, J.G.; Hill, M.G; Allan, D.J. 1995: Persistence of the predatory mite, Hemisarcoptes coccophagus Meyer (Hemisarcoptidae), on low populations of Hemiberlesia lataniae (Signoret) (Diaspididae) in New Zealand. Israel J. Entomol. 29: $297-300$

Greaves, A.J.; Davys, J.W.; Dow, B.W.; Tomkins, A.R.; Thomson, C.; Wilson, D.J. 1994: Seasonal temperatures and the phenology of greedy scale populations (Homoptera: Diaspididae) on kiwifruit vines in New Zealand. N.Z. J. Crop Hort. Sci. (22):7-16.

Grout, T.G.; Du Toit, W.J.; Hofmeyer, J.H.; Richards, G.I. 1989: California red scale (Homoptera: Diaspididae) phenology on citrus in South Africa. J. Econ. Entomol. 82: 793-798

Hill, M.G.; Allan, D.J. 1990: Winter cleanup sprays for latania scale (Hemiberlesia lataniae) on Lombardy poplar shelter in kiwifruit orchards. Proc. $43^{\text {th }}$ N.Z. Weed and Pest Control Conf.: 252-255.

Lo, P.L.; Blank, R.H. 1989: A survey of armoured scale species (Hemiptera: Diaspididae) in kiwifruit orchards. N. Z. Entomol. (2): 1-4.

McKenzie, H.L. 1956: The armoured scales of California. Bulletin California Insect Survey 5: 208p.

Morales, C.F. 1988: The occurrence of latania scale, Hemiberlesia lataniae (Signoret) (Hemiptera: Diaspididae), in New Zealand. N.Z. J. Exp. Agric. (16): 77-82.

Spiller, D.M.; Wise, K.A.J. 1982: A catalogue (1860-1960) of New Zealand insects and their host plants. Science Information Division, DSIR, Wellington. $260 \mathrm{p}$.

Suckling, D.M.; Wearing, C.H.; Thomas, W.P.; Penman, D.R.; Chapman, R.B. 1984: Insecticide resistance in the lightbrown apple moth: A case for resistance management. Proc. $37^{\text {th }}$ N.Z. Weed and Pest Control Conf.: 248-252. 